\title{
Transcendendo:
}

\section{A Cohort Study of HIV-Infected and Uninfected Transgender Women in Rio de Janeiro, Brazil}

Ana Cristina Garcia Ferreira, ${ }^{1, *}$ Lara Esteves Coelho, ${ }^{1}$ Emilia Moreira Jalil, ${ }^{1}$ Paula Mendes Luz, Ruth K. Friedman, ${ }^{1}$ Maria Regina C. Guimarães, ${ }^{1}$ Rodrigo C. Moreira, ${ }^{1}$ Leonardo F. Eksterman, ${ }^{1}$ Sandra Wagner Cardoso, ${ }^{1}$ Cristiane V. Castro, ${ }^{1}$ Monica Derrico, ${ }^{1}$ Ronaldo I. Moreira, ${ }^{1}$ Biancka Fernandes, ${ }^{1}$ Laylla Monteiro, ${ }^{1}$ Luciana Kamel, ${ }^{1}$ Antonio G. Pacheco, ${ }^{2}$ Valdilea G. Veloso, ${ }^{1}$ and Beatriz Grinsztejn ${ }^{1}$

\begin{abstract}
Purpose: Worldwide, the burden of adverse health conditions is substantial among travestis and transgender women (trans women). Transcendendo, the first trans-specific cohort in a low- or middle-income country, is an open cohort established in August 2015 to longitudinally evaluate the health aspects of trans women aged $\geq 18$ years in Rio de Janeiro, Brazil.

Methods: Study visits occur on an annual basis. Data on sociodemographics, behavioral, gender transition, affirmation procedures, hormone use, discrimination, violence, clinical and mental health, HIV prevention, and care (for those HIV-infected) are collected. Physical examination, anthropometric measurements, and laboratory tests are performed.

Results: As of July 2017, 322 trans women were enrolled in the cohort with a median age of 31.5 years (interquartile range 25.7-39.5), of whom 174 (54\%) were HIV-infected. The Transcendendo baseline information reinforces the scenario of marginalization and deprivation surrounding trans women. Most participants had low income (62.0\% were living with below US\$10.00/day), showed a very high engagement in sex work (78.6\%), and reported increased occurrence of sexual (46.3\%) and physical (54.0\%) violence. Pre-exposure peophylaxis (PReP) was used by $18.8 \%$ of the HIV-uninfected trans women, only through research participation. Positive screening for depression (57.8\%) and problematic use of tobacco (56.6\%), cannabis (28.9\%), cocaine (23.8\%), and alcohol (21.5\%) were high. Almost all participants (94.8\%) reported hormone use at some point, mostly without medical supervision (78.7\%).

Conclusion: Our results describe a context of exclusion experienced by trans women, exposing vulnerabilities of this population in a middle-income country, with poor access to trans-specific care, HIV prevention and care, and mental health care. Addressing transgender experiences and needs can help the development of strategies to diminish stigma, improve health care environment, guide future research on trans morbidities, substance use, and trans-specific interventions to support health-related recommendations. Ultimately, it contributes to close the gaps concerning transgender health and reinforces that trans care cannot be disentangled from the social environment that surrounds trans women.
\end{abstract}

Keywords: cohort; HIV; transgender health; transgender person; transgender woman

\footnotetext{
${ }^{1}$ Evandro Chagas National Institute of Infectious Diseases, Oswaldo Cruz Foundation, Rio de Janeiro, Brazil.

${ }^{2}$ Scientific Computing Program, Oswaldo Cruz Foundation, Rio de Janeiro, Brazil.

*Address correspondence to: Ana Cristina Garcia Ferreira, MD, Evandro Chagas National Institute of Infectious Diseases, Oswaldo Cruz Foundation, Avenida Brasil 4365 Manguinhos, Rio de Janeiro 21040-360, Brazil, E-mail: acgferreira@gmail.com; ana.ferreira.fiocruz@gmail.com

(c) Ana Cristina Garcia Ferreira et al. 2019; Published by Mary Ann Liebert, Inc. This Open Access article is distributed under the terms of the Creative Commons License (http://creativecommons.org/licenses/by/4.0), which permits unrestricted use, distribution, and reproduction in any medium, provided the original work is properly cited.
} 


\section{Introduction}

Worldwide, the burden of adverse health conditions is substantial among transgender women and travestis (trans women)-people who were assigned as male at birth but identify themselves as females. ${ }^{1-4}$ Notwithstanding, they are an underserved group, with several gaps in knowledge regarding their health. ${ }^{2}$ Although there is no definitive definition, the term travesti has historical and political significance in Brazil and is mostly used to refer to people of the feminine spectrum that, in general, do not wish to undergo reassignment. ${ }^{5}$

Estimates showed that the transgender population size is small, ranging from $0.5 \%$ to $0.9 \%$ of the overall population ${ }^{3}$ but, nevertheless, has a disproportionate HIV risk. ${ }^{1}$ A systematic review, using data from 2000 to 2011 , found that HIV prevalence reached $18 \%$ in this population, with a 50 -fold increased odds of infection compared with other adults in the reproductive age. ${ }^{6}$ Some of the highest HIV prevalence rates occur in Latin America, where trans women live in the context of profound social exclusion and is a population most vulnerable to HIV. ${ }^{7}$ This vulnerability is a result of the complex interactions of risks at the individual level (condomless anal sex, substance use, sex work), interpersonal risks (high-risk partner pool), and structural factors (social exclusion, violence, discrimination, unemployment). ${ }^{8,9}$ Recent data showed a high HIV prevalence in this population in 12 Brazilian cities. ${ }^{10}$ One study recently reported $31.2 \%$ HIV prevalence among trans women in Rio de Janeiro, Brazil. $^{11}$

Although trans women are a key population for HIV infection, there are very few tailored prevention and treatment programmes and interventions specifically designed for this population. Historically, trans women were inappropriately grouped with men who have sex with men, which not only hindered the attainment of trans-specific data but also limited their visibility in research and surveillance studies. ${ }^{2,12}$ Surveillance systems do not usually identify transgender respondents, and scientific data are still scarce, with a dearth of longitudinal data. ${ }^{2}$ To fill this gap, we established the Oswaldo Cruz Foundation (Fiocruz) Transgender Health Clinical Cohort (Transcendendo) with the primary aim of studying the health outcomes in trans women living in Rio de Janeiro, Brazil. We here describe cohort procedures in addition to trans women baseline characteristics.

\section{Methods}

\section{Ethic statement}

The study was reviewed and approved by the Evandro Chagas National Institute of Infectious Diseases ethics review board at Fiocruz. All information was deidentified before analysis. All participants signed an informed consent form before study procedures. The files have highly restricted access by any personnel.

\section{Study population}

Transcendendo is a prospective, open, clinic-based cohort, established in August 2015, to longitudinally evaluate health outcomes among trans women. Inclusion criteria are: $\geq 18$ years of age and self-reported gender identity different from male sex assigned at birth. We present the baseline data of participants enrolled from August 2015 to July 2017.

Study participants were derived from three sources, as shown in Figure 1: (1) referral from Transcender, a respondent-driven sampling (RDS) study conducted at our clinic in Fiocruz, ${ }^{11}$ (2) trans women who reached the site seeking participation in other studies or HIV prevention or care, and (3) from the Fiocruz HIV Clinical Cohort, described elsewhere. ${ }^{13}$

Trans women are a vulnerable population hardly accessible by classic sampling frame techniques for multiple reasons. ${ }^{14} \mathrm{~A}$ useful nonprobabilistic methodology for these populations is RDS, which is a chain referral method of recruitment. We employed RDS to recruit 345 trans women to Transcender from August 2015 to January 2016, 271 (78.5\%) of whom were enrolled in Transcendendo. Every participant from Transcender had an initial visit scheduled for Transcendendo, but 74 (21.5\%) did not return to the appointment (21 were not reachable with the contact information provided, 3 were no longer living in Rio de Janeiro, 14 declined to participate, and 36 were rescheduled for a second appointment but never returned).

After Transcender's closure, inclusion into our cohort was modified to any trans woman who spontaneously sought medical HIV care or prevention at our clinic. During the period from February 2016 to July 2017, 37 trans women reached our services and were enrolled in the cohort. Additionally, during this period, we reviewed the electronic records of patients from the Fiocruz HIV Clinical Cohort to identify potential candidates, which we defined as participants who were assigned as male at birth and had any mention of the term "trans" or social names in their files. This review process identified 70 trans women: as of July 2016, 12 


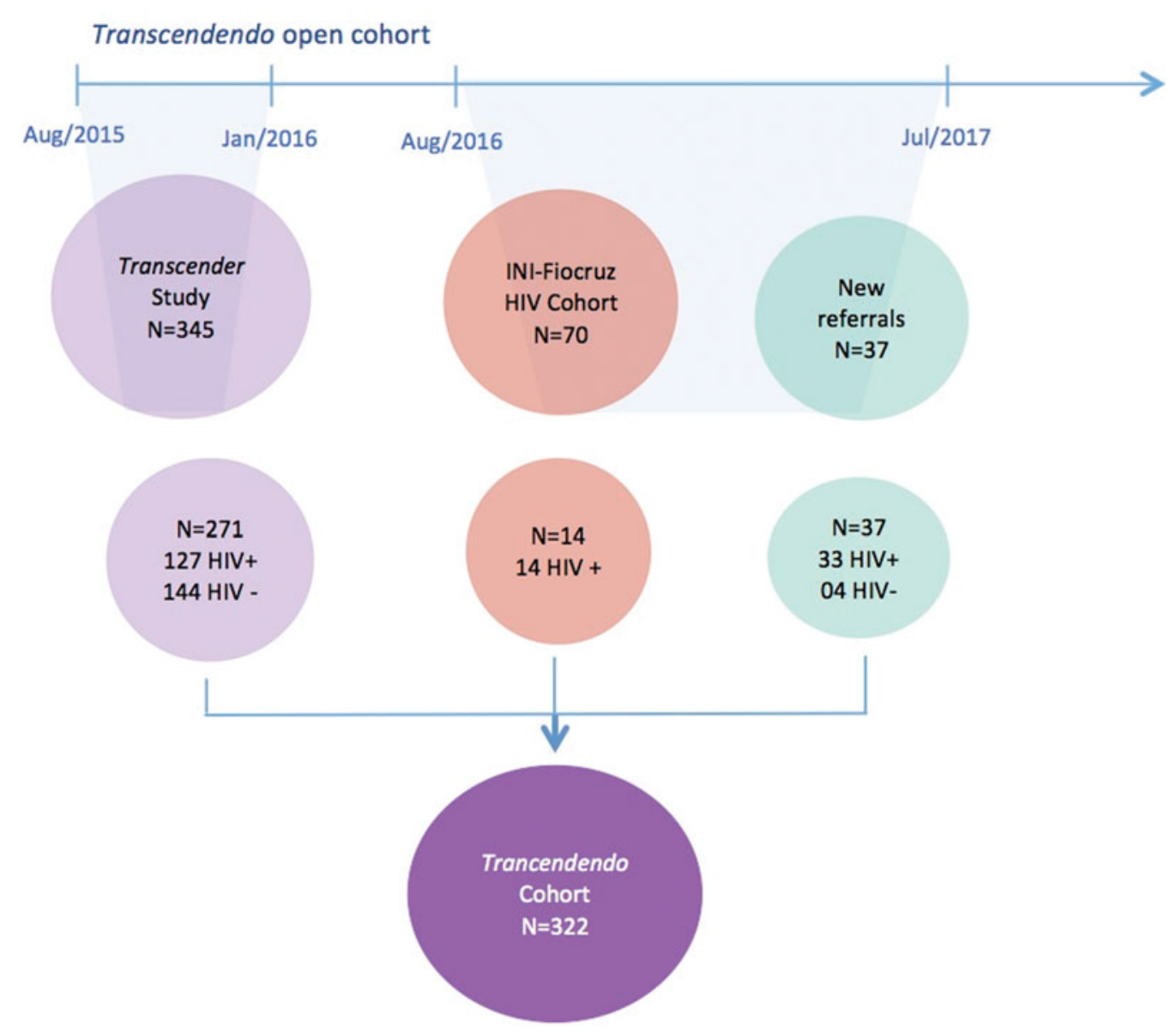

FIG. 1. Transcendendo participant flowchart, Rio de Janeiro, Brazil, 2015-2017.

are deceased, 15 were lost to follow-up, and 34 were potential participants. We tried to invite these 34 participants to join the cohort; 14 got enrolled as of July 2017. For the remaining 20 participants, although we tried to contact them, we hardly had any success.

To improve trans women engagement and retention, our setting presented itself as a welcoming, genderaffirming environment by using preferred names and pronouns; respecting gender identities, diversity, and expressions; providing safe, gender-neutral toilets; publicizing trans-affirming posters; offering continuous staff training on gender issues; and enabling friendly interactions between trans women and site staff. Finally, we established partnerships to facilitate social demands, such as adjustment of names in the documents, legal assistance, and providing access to potential interventions that could reduce stigma and socioeconomic disparities.
Study procedures

Measures. Study visits occur on an annual basis (Table 1). Each of these visits comprises face-to-face interviews using structured questionnaires, performed by trained professionals $(\sim 90 \mathrm{~min})$, to collect detailed data on sociodemographics, sexual behavior, gender affirmation procedures, hormone and antiretroviral use (for HIV prevention or treatment), discrimination and violence, alcohol, tobacco, and drug use, physical and mental health, history of sexually transmitted infections (STIs), HIV testing history, HIV prevention, and HIV care information (for those HIV-infected).

Procedures during visits also included clinical evaluation, as well as morbidity and medication history. We used self-reported information (prior medical diagnosis or use of specific treatment) or current results/measurements to define hypertension, diabetes, and dyslipidemia, as follows: (1) hypertension: average diastolic blood 
Table 1. Study Procedures: Transcendendo Cohort

\begin{tabular}{|c|c|c|}
\hline Study procedures & $\begin{array}{c}\text { Entry } \\
\text { evaluation }\end{array}$ & $\begin{array}{c}\text { Postentry } \\
\text { annual } \\
\text { evaluation }\end{array}$ \\
\hline Consenting & $\mathrm{x}$ & \\
\hline \multicolumn{3}{|l|}{ Face-to-face interviews } \\
\hline Sociodemographic information & $\mathrm{x}$ & $\mathrm{x}$ \\
\hline Gender transition & $\mathrm{x}$ & \\
\hline Gender affirmation procedures & $\mathrm{x}$ & $\mathrm{x}$ \\
\hline Sexual behavior ${ }^{\mathrm{a}}$ & $\mathrm{x}$ & $x$ \\
\hline Discrimination $^{\mathrm{b}}$ and violence ${ }^{c}$ & $x$ & $x$ \\
\hline History of sexually transmitted infections & $\mathrm{x}$ & $\mathrm{x}$ \\
\hline HIV testing history & $\mathrm{x}$ & $\mathrm{x}$ \\
\hline $\begin{array}{l}\text { HIV prevention knowledge and risk } \\
\text { perception }\end{array}$ & $\mathrm{x}$ & $\mathrm{x}$ \\
\hline Substance use & $x$ & $x$ \\
\hline ASSIST questionnaire & $\mathrm{x}$ & \\
\hline Depression screening CES-10 & $\mathrm{x}$ & \\
\hline \multicolumn{3}{|l|}{ Clinical evaluation } \\
\hline Physical, mental, and medical evaluation & $\mathrm{x}$ & $x$ \\
\hline Hormone use & $x$ & $\mathrm{x}$ \\
\hline HIV care information ${ }^{d}$ & $\hat{x}$ & $\hat{x}$ \\
\hline $\begin{array}{l}\text { Antiretroviral use (prevention or } \\
\text { treatment) }\end{array}$ & $\mathrm{x}$ & $\mathrm{x}$ \\
\hline Medication history & $\mathrm{x}$ & $\mathrm{x}$ \\
\hline Anthropometric measurements & $\mathrm{x}$ & $\mathrm{x}$ \\
\hline \multicolumn{3}{|l|}{ Laboratory testing } \\
\hline Metabolic panel & $\mathrm{x}$ & $\mathrm{x}$ \\
\hline Serum hormone levels & $\mathrm{x}$ & \\
\hline Hematology and chemistry tests & $\mathrm{x}$ & $\mathrm{x}$ \\
\hline STI testing & $\mathrm{x}$ & $\mathrm{x}$ \\
\hline Counseling and HIV testing ${ }^{e}$ & $\mathrm{x}$ & $\mathrm{x}$ \\
\hline HIV drug resistance tests & $\mathrm{x}$ & \\
\hline $\mathrm{CD}^{+} / \mathrm{CD}^{+}$count and plasma HIV RNA ${ }^{\mathrm{d}}$ & $x$ & $x$ \\
\hline $\begin{array}{l}\text { Stored serum and plasma for future } \\
\text { assessments }\end{array}$ & $\mathrm{x}$ & $\mathrm{x}$ \\
\hline
\end{tabular}

aSexual behavior was assessed through questions regarding age of sexual debut, sexual orientation, sex work, practices of receptive and insertive anal sex, vaginal sex, use of condoms, and number of partners.

${ }^{b}$ Discrimination was assessed by the participant's perception of being discriminated against in the following settings: at home, school, work, health care, and on the street.

'Violence was assessed with questions on sexual and physical violence ever in life and in the past year.

${ }^{\mathrm{d}}$ For HIV-infected participants.

${ }^{\mathrm{F}}$ For HIV-uninfected participants.

pressure $\geq 90 \mathrm{mmHg}$ or average systolic blood pressure $\geq 140 \mathrm{mmHg},{ }^{15}$ (2) diabetes: plasma nonfasting glucose $\geq 200 \mathrm{mg} / \mathrm{dL}$ or glycosylated hemoglobin $\geq 6.5 \%,{ }^{16}$ (3) dyslipidemia: non-HDL-cholesterol $\geq 160 \mathrm{mg} / \mathrm{dL} .{ }^{17} \mathrm{We}$ considered overweight and obesity as body mass index between 25 and $29.9 \mathrm{~kg} / \mathrm{m}^{2}$ and $\geq 30 \mathrm{~kg} / \mathrm{m}^{2}$, respectively.

At baseline visit, we performed some additional procedures. We assessed information on gender perception, gender transition, and engagement in sex work. Additionally, participants responded to two validated instruments to assess depression and substance use. ${ }^{18}$ We screened depression using the 10-item Center for Epidemiologic Studies Depression Scale (CES-D) ${ }^{19-21}$ and defined it with a score of $\geq 10$. Problematic sub- stance use was defined when the Alcohol, Smoking, and Substance Involvement Screening Test (ASSIST) scored moderate or high risk of experiencing health problems and demanding intervention. ${ }^{22}$

For HIV-infected trans women, clinical information included date of first HIV-positive test, all antiretroviral therapy (ART) used, as well as other concomitant medications, history of non-AIDS-related comorbidities, and AIDS-defining illnesses, classified according to the CDC. ${ }^{23}$

Laboratory procedures. Procedures during visits also comprised laboratory testing, as described in Table 1, including STI testing (syphilis, rectal Chlamydia trachomatis and Neisseria gonorrhea, hepatitis B and C), and sample storage at all visits for future assessments. For HIV-infected trans women, we measured $\mathrm{CD}^{+}{ }^{+}$and $\mathrm{CD}^{+}$cells and plasma viral load (VL) during every visit and performed HIV drug resistance test at baseline. For HIV-uninfected trans women who reported condomless anal intercourse in the past 30 days and have a negative HIV rapid test, we also offered pooled HIV RNA testing to identify acute HIV infection.

Additional data collection. We also systematically collected data on hospital admissions (causes and length of stay) and causes of death. For all deaths that occurred, we used a uniform coding system, adapted from the CoDe ("Coding of Death in HIV") method, ${ }^{24}$ to revise near-death patient information either for the HIV-infected or uninfected participants. The method includes detailed data collection on the causes of death and contributing factors and a centralized review process of the collected data. Information regarding vital status was regularly checked using the patients' medical charts, via active contact with individuals and family members, and by linkage with the Rio de Janeiro state mortality database, using a previously validated algorithm. ${ }^{25}$

\section{Study definitions}

Sociodemographic characteristics. We categorized self-reported gender identity as "woman," "transgender woman," "travesti," and "other definitions." "Travesti" is a term used in Brazil that mostly refers to individuals assigned as male at birth and have feminine gender expression, but do not identify as women, and generally do not wish to undergo feminizing vaginoplasty. ${ }^{5}$ Educational level included four categories, based on the number of years of formal education. Per-person daily income 
followed the classification of poverty. ${ }^{26}$ Participants born outside Rio de Janeiro State were classified as internal migrants.

STI diagnosis. We considered active syphilis as a positive treponemal test (rapid immunochromatographic syphilis point-of-care or microhemagglutination assay for Treponema pallidum) plus a positive nontreponemal test Venereal Disease Research Laboratory (VDRL) with titers of at least $1 / 8$ at baseline. Active hepatitis B was defined as a positive $\mathrm{HB}$ antigen and a negative anti-HB antigen. $\mathrm{HCV}$ prevalence was defined as positive anti-HCV.

Trans-specific characteristics. Feminizing procedures included gender-affirming surgeries (breast augmentation, facial feminization, tracheal shave) and sex reassignment surgeries (SRS) (penectomy, orchiectomy, vaginoplasty). We classified the use of feminizing hormonal therapy (FHT) as "never," "current," or "former," according to the report within the last 30 days. As trans women might be using more than one regimen; we inquired on every hormonal medication and classified them as "ethinylestradiol," "intramuscular estradiol plus progestogen," "estradiol plus antiandrogen," or "other." We considered "estradiol plus antiandrogen" as an adequate FHT, according to current guidelines $^{27-30}$ and the use of ethinylestradiol or intramuscular progestagen as inadequate, as these substances are not recommended by international guidelines. ${ }^{27-30}$ We considered serum testosterone and estradiol levels, respectively, of $<55 \mathrm{ng} / \mathrm{dL}$ and between 40 and $199 \mathrm{pg} /$ $\mathrm{mL}$ as the target levels for FHT. ${ }^{31}$

\section{Statistical analysis}

Descriptive characteristics of cohort participants are given as counts, percentages, medians, and interquartile ranges (IQR). We compared baseline characteristics of participants by HIV status using chi-squared test for categorical variables and Kruskal-Wallis test for continuous variables. In addition, we compared clinical and laboratory data for HIV-infected trans women by age strata.

\section{Results}

As described in Table 2, 322 trans women were enrolled from August 2015 to July 2017, of whom 174 (54.0\%) were HIV-infected. Median age was 31.5 years (IQR 25.7-39.5). The majority of them selfdeclared as nonwhite. Overall, participants reported low schooling and income, with $62.0 \%$ of them living with below US\$ 10.00 per day. Sexual debut occurred before the age of 10 years for $70.2 \%$ of the participants. We observed a high prevalence of physical $(n=174$; $54.0 \%)$ and sexual $(n=149 ; 46.3 \%)$ violence. Out of the 149 participants who reported a history of sexual violence, $95(63.8 \%)$ informed that it occurred the first time before the age of 18 years, and for 58 (38.9\%), it occurred before the age of 14 years. The frequency of past engagement in sex work was high (78.6\%). Overall, $186(57.6 \%)$ of trans women had a positive treponemal test, and $27.0 \%$ had active syphilis at baseline. The prevalence of active rectal C. trachomatis and N. gonorrhea was $12 \%$ and $6 \%$, respectively, and few had active hepatitis B and C. From the 148 HIV-uninfected participants, only 18 (12.2\%) were on HIV pre-exposure prophylaxis (PrEP), all of them via participation in a PrEP demonstration study. Hypertension (17.9\%) was one of the most common chronic nontransmissible comorbidity. We identified depression in $58 \%$ of the participants; depression was significantly higher among the HIV-infected $(p=0.05)$.

Compared to those HIV-uninfected, HIV-infected trans women had lower schooling and income, reported more engagement in sex work, and had higher rates of STIs. HIV-uninfected and HIV-infected trans women significantly differed in gender identity, as HIV-uninfected trans women more frequently selfreported as women $(33.1 \%$ vs. $14.4 \%)$ and less frequently as travestis $(29.1 \%$ vs. $48.8 \%)$ and had higher obesity/overweight prevalence (Table 2).

A high number of trans women reported problematic use of tobacco $(56.6 \%)$, cannabis $(28.9 \%)$, cocaine (23.8\%), and alcohol (21.5\%) (Table 2). Compared to those HIV-uninfected, higher proportions of HIVinfected trans women had problematic use of cannabis, cocaine, and tobacco.

The majority of trans women perceived themselves as transgender during childhood $(63.7 \%$ aged $\leq 10)$, and the median age of gender transition was 16 years (IQR 14-18) (Table 3). Any feminizing procedure was reported by $41.0 \%$, with only $5.9 \%$ reporting SRS. SRS was more frequent among HIV-uninfected than in HIV-infected trans women. About a third had gender-affirming surgery, and $49.1 \%$ reported prior industrial silicone filler injection. Most trans women have used hormones at some point, and around half (49.1\%) were on current FHT, mostly nonprescribed by health professionals (78.7\%). Fewer HIV-infected trans women were currently using hormones (both prescribed and nonprescribed) compared with HIV-uninfected trans 
Table 2. Baseline Sociodemographic and Clinical Characteristics of Transgender Women by HIV Serostatus-Transcendendo Cohort, Rio de Janeiro, Brazil, 2015-2017

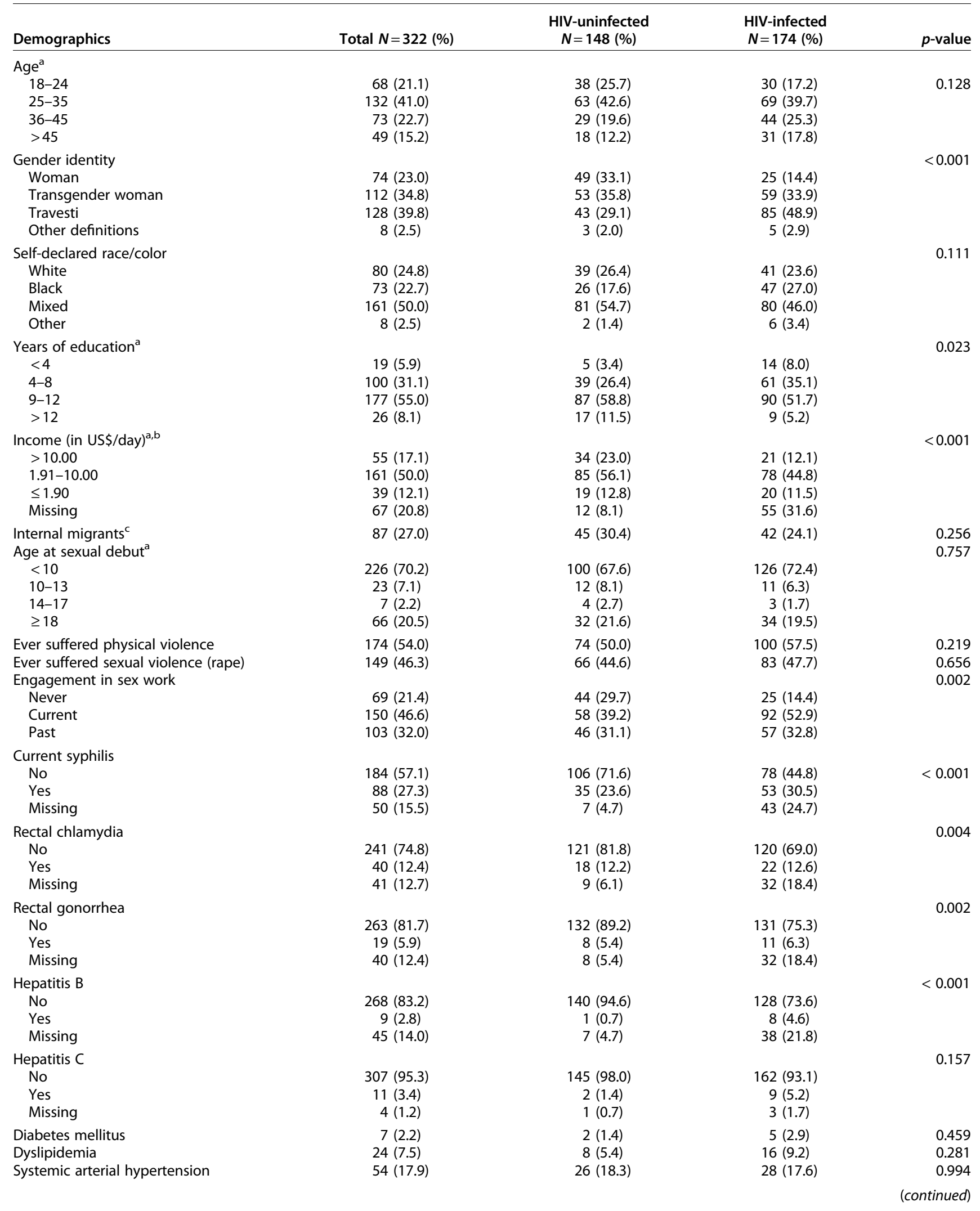


Table 2. (Continued)

\begin{tabular}{|c|c|c|c|c|}
\hline Demographics & Total $N=322(\%)$ & $\begin{array}{l}\text { HIV-uninfected } \\
\quad N=148(\%)\end{array}$ & $\begin{array}{l}\text { HIV-infected } \\
N=174(\%)\end{array}$ & $p$-value \\
\hline \multicolumn{5}{|l|}{ Obesity/overweight } \\
\hline No & $170(52.8)$ & $73(49.3)$ & $97(55.7)$ & \\
\hline Yes & $138(42.9)$ & $73(49.3)$ & $65(37.4)$ & 0.011 \\
\hline Missing & $14(4.3)$ & $2(1.4)$ & $12(6.9)$ & \\
\hline Depression $^{d}$ & $186(57.8)$ & $77(52.0)$ & $109(62.6)$ & 0.054 \\
\hline \multicolumn{5}{|c|}{ Problematic use of substances (ASSIST score $\left.{ }^{d}\right)^{e}$} \\
\hline Alcohol & $55(21.5)$ & $18(16.4)$ & $37(25.3)$ & 0.115 \\
\hline Tobacco & $145(56.6)$ & $54(49.1)$ & $91(62.3)$ & 0.047 \\
\hline Cannabis & $74(28.9)$ & $22(20.0)$ & $52(35.6)$ & 0.010 \\
\hline Cocaine & $61(23.8)$ & 15 (13.6) & $46(31.5)$ & 0.002 \\
\hline Amphetamine stimulants & $7(2.7)$ & $2(1.8)$ & $5(3.4)$ & 0.702 \\
\hline
\end{tabular}

${ }^{\mathrm{a} C o n t i n u o u s ~ v a r i a b l e s ~ w e r e ~ r e c l a s s i f i e d ~ a s ~ c a t e g o r i c a l . ~}$

${ }^{\mathrm{b}} \mathrm{US} \$ 1.00=\mathrm{R} \$ 3.85$.

'Participants born outside Rio de Janeiro state were classified as internal migrants.

${ }^{\mathrm{d}}$ Screening by CES-D10.

${ }^{e}$ ASSIST score of $11+$ for alcohol and $4+$ for other substances.

ASSIST, Alcohol, Smoking and Substance Involvement Screening Test.

Table 3. Transitioning Characteristics of Transgender Women According to HIV Serostatus-Transcendendo Cohort, Rio de Janeiro, Brazil, 2015-2017

\begin{tabular}{|c|c|c|c|c|}
\hline Transitioning characteristics & Total $N=322$ & HIV-uninfected $N=148$ & HIV-infected $N=174$ & $p$ \\
\hline \multicolumn{5}{|l|}{ Age of gender perception ${ }^{a}$} \\
\hline$\leq 7$ & $112(34.8)$ & $56(37.8)$ & $56(32.2)$ & 0.254 \\
\hline $8-10$ & $93(28.9)$ & 39 (26.4) & $54(31.0)$ & \\
\hline $11-13$ & $66(20.5)$ & 29 (19.6) & $37(21.3)$ & \\
\hline$\geq 14$ & $47(14.6)$ & $24(16.2)$ & $23(13.2)$ & \\
\hline Missing & $4(1.2)$ & $0(0.0)$ & $4(2.3)$ & \\
\hline \multicolumn{5}{|l|}{ Age of gender transition ${ }^{a}$} \\
\hline$<14$ & $59(18.3)$ & $24(16.2)$ & $35(20.1)$ & 0.151 \\
\hline $14-17$ & $148(46.0)$ & $63(42.6)$ & $85(48.9)$ & \\
\hline$\geq 18$ & $114(35.4)$ & $61(41.2)$ & $53(30.5)$ & \\
\hline Missing & $1(0.3)$ & $0(0.0)$ & $1(0.6)$ & \\
\hline Ever performed gender affirmation procedures ${ }^{\mathrm{b}}$ & $132(41.0)$ & 59 (39.9) & $73(42.0)$ & 0.790 \\
\hline Ever had sex reassignment surgery ${ }^{\mathrm{b}}$ & $19(5.9)$ & $15(10.1)$ & $4(2.3)$ & 0.006 \\
\hline Ever injected fillers & $158(49.1)$ & $57(38.5)$ & $101(58.0)$ & $<0.001$ \\
\hline \multicolumn{5}{|l|}{ Hormone use } \\
\hline Current & $158(49.1)$ & $88(59.5)$ & $70(40.2)$ & 0.002 \\
\hline Past & $147(45.7)$ & $52(35.1)$ & $95(54.6)$ & \\
\hline Never & $16(5.0)$ & $8(5.4)$ & $8(4.6)$ & \\
\hline Missing & $1(0.3)$ & $0(0.0)$ & $1(0.6)$ & \\
\hline Medically guided hormone use & & & & 0.014 \\
\hline Never & $240(78.7)$ & $100(71.4)$ & $140(84.8)$ & \\
\hline Current & $29(9.5)$ & $21(15.0)$ & $8(4.8)$ & \\
\hline Past & $19(6.2)$ & $10(7.1)$ & $9(5.5)$ & \\
\hline Missing & $17(5.6)$ & $9(6.4)$ & $8(4.8)$ & \\
\hline Current use of ethinylestradiol $^{\mathrm{C}}$ & $59(37.3)$ & $35(39.8)$ & $24(34.3)$ & 0.587 \\
\hline Current use of IM estradiol plus progestagen ${ }^{\mathrm{C}}$ & $91(57.6)$ & $45(51.1)$ & $46(65.7)$ & 0.093 \\
\hline Current use of estradiol plus antiandrogen ${ }^{c}$ & $22(13.9)$ & $16(18.2)$ & $6(8.6)$ & 0.133 \\
\hline \multicolumn{5}{|l|}{ Total testosterone $\mathrm{a}^{\mathrm{a}, \mathrm{c}}$} \\
\hline At target level & $89(56.3)$ & $53(60.2)$ & $36(51.4)$ & 0.221 \\
\hline Above target level & $64(40.5)$ & 34 (38.6) & $30(42.9)$ & \\
\hline Missing & $5(3.2)$ & $1(1.1)$ & $4(5.7)$ & \\
\hline \multicolumn{5}{|l|}{ Estradiol $^{\mathrm{a}, \mathrm{c}}$} \\
\hline Below target level & $80(50.6)$ & $47(53.4)$ & $33(47.1)$ & 0.433 \\
\hline At target level & $47(29.7)$ & $26(29.5)$ & $21(30.0)$ & \\
\hline Above target level & $26(16.5)$ & $14(15.9)$ & $12(17.1)$ & \\
\hline Missing & $5(3.2)$ & $1(1.1)$ & $4(5.7)$ & \\
\hline
\end{tabular}

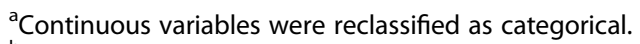

${ }^{\mathrm{b}}$ Breast augmentation, facial feminization, tracheal shave, or sex reassignment surgery (vaginoplasty, penectomy, and oorchiectomy).

${ }^{\mathrm{C}}$ Evaluated to trans women currently using hormones $(n=158)$.

IM, intramuscular. 
women $(40.2 \%$ vs. $59.5 \% ; p<0.001)$. Among trans women currently using hormones $(N=158)$, most of them were using inadequate FHT $(57.6 \%$ were using intramuscular estradiol plus progestagen, $37.3 \%$ reported current use of ethinylestradiol). Only $13.9 \%$ reported the use of an adequate regimen (estradiol plus antiandrogen) and 9.5\% were under current medical-guided hormonal use. Among trans women currently on hormones, $56.3 \%$ and $29.7 \%$ achieved the target testosterone and estradiol levels, respectively; $16.5 \%$ had estradiol levels higher than recommended.

Among HIV-infected trans women, median time since HIV diagnosis was 1.8 years (IQR $0-7.3$ ); the median $\mathrm{CD}^{+}{ }^{+}$count was $582 \mathrm{cells} / \mathrm{mm}^{3}$ (IQR 372-800); and $60 \%$ of them were using ART. Out of the $70 \mathrm{HIV}$-infected trans women who were not on ART, 38.6\% (27) had been diagnosed with HIV on the same day of Transcendendo enrollment, $57.1 \%$ (40) had already been diagnosed with HIV but had never used ART, and 4.3\% (3) had been on ART before but were not currently using it. Among those currently using ART, 67.3\% had undetectable VL (Table 4). ART use was less frequent among younger HIV-infected trans women, but among those who used ART, they were more likely to have undetectable VL: $80.0 \%$ among those aged $18-24$ versus $57.1 \%$ among those aged $\geq 46$. Forty (23.0\%) HIV-infected trans women reported a previous AIDS-defining illness; $16.7 \%$ reported previous tuberculosis.

\section{Discussion}

Our study presents baseline characteristics of the Transcendendo cohort. Our findings reinforce trans women as a disadvantaged and disenfranchised group, with multiple needs that go beyond health itself. Trans women bear a disproportionate burden of adverse outcomes that are sparingly evaluated, mostly by crosssectional studies. ${ }^{2}$ Although transgender populations face adverse experiences worldwide, the context of marginalization and social exclusion may be even worse in a low- or middle-income country (LMIC), with poor access to hormone use supervision, genderrelated interventions, HIV prevention and care, and support for problematic substance use. Transcendendo is the first Latin-American cohort to evaluate the social, demographic, and clinical aspects of HIV-infected and HIV-uninfected trans women.

\section{Sociodemographic context of exclusion,}

discrimination, and violence

Our results reveal that the participants of Transcendendo have low education level and income, experience high physical and sexual violence rates, and frequently engage in sex work. These unfavorable conditions are in accordance with other authors. ${ }^{32-35}$ The social context that trans women face is a combination of diverse related factors such as exclusion, stigma, violence, lack of justice, and poor access to education and

Table 4. Clinical Characteristics of HIV-Infected Transgender Women, According to Age-Transcendendo Cohort, Rio de Janeiro, Brazil, 2015-2017

\begin{tabular}{|c|c|c|c|c|c|c|}
\hline Clinical characteristics & $\begin{array}{c}\text { Total } \\
N=174(\%)\end{array}$ & $\begin{array}{c}18-24 \\
N=30(\%)\end{array}$ & $\begin{array}{c}25-35 \\
N=69(\%)\end{array}$ & $\begin{array}{c}36-45 \\
N=44(\%)\end{array}$ & $46+N=31(\%)$ & $p$ \\
\hline \multicolumn{7}{|l|}{ Mode of HIV acquisition } \\
\hline Sex with men & $161(92.5)$ & $27(90.0)$ & $66(95.7)$ & $43(97.7)$ & $25(80.6)$ & 0.042 \\
\hline IDU & $2(1.1)$ & $0(0.0)$ & $0(0.0)$ & $0(0.0)$ & $2(6.5)$ & \\
\hline Other/unknown & $11(6.5)$ & $3(10.0)$ & $3(4.3)$ & $1(2.3)$ & $4(12.9)$ & \\
\hline \multicolumn{7}{|l|}{ Current CD4 count (cells $\left./ \mathrm{mm}^{3}\right)^{\mathrm{a}}$} \\
\hline$<250$ & $21(12.1)$ & $2(6.7)$ & $11(15.9)$ & $4(9.1)$ & $4(12.9)$ & 0.884 \\
\hline $251-500$ & $36(20.7)$ & $6(20.0)$ & $15(21.7)$ & $9(20.5)$ & $6(19.4)$ & \\
\hline$>500$ & $84(48.3)$ & $16(53.3)$ & $29(42.0)$ & $25(56.8)$ & $14(45.2)$ & \\
\hline Missing & $33(19.0)$ & $6(20.0)$ & $14(20.3)$ & $6(13.6)$ & $7(22.6)$ & \\
\hline \multicolumn{7}{|l|}{ Currently on ART } \\
\hline No & $70(40.2)$ & $25(83.3)$ & $36(52.2)$ & $6(13.6)$ & $3(9.7)$ & $<0.001$ \\
\hline Yes & $104(59.8)$ & $5(16.7)$ & $33(47.8)$ & $38(86.4)$ & $28(90.3)$ & \\
\hline \multicolumn{7}{|c|}{ Current HIV RNA viral load (copies/mL) $(N=103)^{\mathrm{b}}$} \\
\hline$<40$ & $70(67.3)$ & $4(80.0)$ & $23(69.7)$ & $27(71.1)$ & $16(57.1)$ & 0.775 \\
\hline$\geq 40$ & $22(21.2)$ & $1(20.0)$ & $5(15.2)$ & $8(21.1)$ & $8(28.6)$ & \\
\hline Missing & $12(11.5)$ & $0(0.0)$ & $5(15.2)$ & $3(7.9)$ & $4(14.3)$ & \\
\hline Had previous AIDS-defining illness & $40(23.0)$ & $2(6.7)$ & $8(11.6)$ & $17(38.6)$ & $13(41.9)$ & $<0.001$ \\
\hline Had previous TB $^{\mathrm{C}}$ & $29(16.7)$ & $2(6.7)$ & $11(15.9)$ & $11(25.0)$ & $10(32.3)$ & 0.051 \\
\hline
\end{tabular}

${ }^{\mathrm{a} C}$ Continuous variables were reclassified as categorical.

${ }^{b}$ Calculated only for those on ART.

${ }^{c}$ After HIV diagnosis.

ART, antiretroviral therapy; IDU, injection drug use. 
employment, which usually exacerbate one another and increase vulnerability to $\mathrm{HIV}$ and other diseases. ${ }^{36}$ Although Brazilian laws protect transgender rights, transphobia is ingrained diffusely, and Brazil is the leading country of homicides of transgender people, accounting for almost $40 \%$ of all reported murders of transgender people worldwide. ${ }^{37}$

\section{Mental and physical health}

We found that depression was very common in our cohort (58\%), comparable to those described using similar screening scales (prevalence between $44 \%$ and $49 \%)^{14,38,39}$ and more prevalent than observed in the cisgender Brazilian population (13.2-20.2\%). ${ }^{40,41}$ This finding is in accordance with data from Canada and the United States, which observed a higher prevalence of depression among trans women compared to cisgender population. ${ }^{14,42}$ The factors associated with gender minority stress, such as victimization, rejection, discrimination, and nonaffirmation of gender identity, seem to be associated with depression and other mental health conditions. ${ }^{43,44}$ We found a lower prevalence of hypertension compared to the data from the general population of Brazil, ${ }^{45}$ which may be due to the lower age of our sample. Additionally, diabetes and dyslipidemia were less frequent in our population, compared with other general population studies in Brazil $^{46,47}$ and with the Canadian trans women cohort. ${ }^{14}$ These contrasts may again be related to the demographic characteristics of the populations, such as age and gender, as well as to the differences in definitions adopted by each study.

\section{Trans-specific interventions}

Most trans women used hormones at some point, almost always nonprescribed by health professionals, at higher levels than described in the United States. ${ }^{48-51} \mathrm{We}$ also identified alarming rates of industrial silicon filler injection and lower rates of SRS than described in other countries. ${ }^{52,53}$ These differences might reflect worse access to general and transgender-specific health care. Genderaffirming hormone therapy is the main intervention sought by transgender people, since it allows the development of characteristics compatible with their gender identity. ${ }^{28}$ FHT is considered safe under medical supervision, ${ }^{54}$ but nonprescribed hormones are associated with the uptake of inadequate compounds, improper dosing, and lack of monitoring. ${ }^{48}$ In our cohort, most trans women did not achieve the recommended levels of hormones; more than a third was using ethinylestradiol (37.3\%) and some had higher estradiol levels than recommended. Ethinylestradiol is not recommended to feminization due to its high thrombogenic risk. ${ }^{54}$ The combination of intramuscular estradiol plus progestagen, commonly used in our setting, is understudied, but might be associated with cardiovascular disease and breast cancer in postmenopausal women. ${ }^{55}$ In summary, the high rates of inadequate use of hormones in our sample is alarming and points to the unmet needs of this underprivileged group.

\section{HIV infection}

Compared with those HIV-uninfected, HIV-infected trans women had lower educational levels, were involved in more sex work, and reported problematic use of some substances. Forty percent were not on ART, especially the younger population with two-thirds of those on ART having an undetectable VL. These results highlight the need for better retention in care, which will ultimately impact HIV transmission. HIV epidemic among trans women is considered a syndemic condition, which generally develops in the context of social disadvantage and inequality. ${ }^{4}$ It has been suggested that syndemics may also explain the difficulties in the treatment of HIV infection apart from other coexisting social, behavioral, and medical conditions that limit successful and sustained engagement in health care. ${ }^{12}$

\section{Strengths and limitations}

The main strengths of this study are the unique evaluation of an extremely marginalized and vulnerable population, the use of a standardized data collection platform, and the systematic medical and laboratory assessments. Very few studies have evaluated trans women longitudinally, none in LMICs. In addition, trans women are a hard-to-reach and hard-to-retain population for health care. ${ }^{56-58}$ So, to improve retention and outcome assessment, we established a welcoming, gender-affirming setting, which facilitated the engagement and retention of trans women. Also, we established a linkage with the state-level mortality database to improve lost to followup evaluation in our population, since it can help identify deaths not reported to our study team. Our study also has some limitations. Foremost, Transcendendo is an open cohort restricted to a convenience sample from the Rio de Janeiro population, and therefore the findings cannot be generalizable to the whole trans women population. Also, as this is a clinic-based cohort, procedures are linked to medical care, which may lead to some missing data. However, to minimize these occurrences, our study procedures are carried out annually. 


\section{Conclusions}

Transcendendo is a unique opportunity to longitudinally assess transgender health outcomes among young trans women from a LMIC, including issues regarding hormone and antiretroviral use, incident comorbidities, and complications such as metabolic and cardiovascular events. Baseline results contribute to bridging the gaps concerning transgender people's health and reinforce that transgender care cannot be disentangled from the social environment that surrounds trans women. HIV infection is a major concern among trans women, but transgender members claim that their marginalization needs to be addressed as the highest priority to succeed in a response to $\mathrm{HIV}^{36}$ Transcendendo results may guide future research and trans-specific interventions by addressing transgender vulnerabilities and needs and supporting the development of strategies to diminish stigma, improve health care environment, guide future research on trans morbidities, substance use, feminizing hormone therapy, and trans-specific interventions to support health-related recommendations.

\section{Acknowledgments}

We acknowledge all of the Transcendendo team and participants. The study was reviewed and approved by the Evandro Chagas National Institute of Infectious Diseases ethics review board at Fiocruz. Funding: This work was supported by Fiocruz PMA (Programa de Politicas Públicas e Modelos de Atenção à Saúde) and the Brazilian Ministry of Health.

\section{Author Disclosure Statement}

No competing financial interests exist.

\section{References}

1. Poteat T, Reisner SL, Radix A. HIV epidemics among transgender women. Curr Opin HIV AIDS. 2014;9:168-173.

2. Reisner SL, Poteat T, Keatley J, et al. Global health burden and needs of transgender populations: a review. Lancet Lond Engl. 2016;388:412-436.

3. Poteat T, Scheim A, Xavier J, et al. Global epidemiology of HIV infection and related syndemics affecting transgender people. J Acquir Immune Defic Syndr. 2016;72 Suppl 3:S210-S219.

4. Parsons JT, Millar BM, Moody RL, et al. Syndemic conditions and HIV transmission risk behavior among HIV-negative gay and bisexual men in a U.S. national sample. Health Psychol. 2017;36:695-703.

5. Kulick D. Travesti: Prostitution, Sex, Gender, and Culture in Brazil [in Portuguese]. Rio de Janeiro: Editora Fiocruz, 2008.

6. Baral SD, Poteat T, Strömdahl S, et al. Worldwide burden of HIV in transgender women: a systematic review and meta-analysis. Lancet Infect Dis. 2013;13:214-222.

7. Silva-Santisteban A, Eng S, de la Iglesia G, et al. HIV prevention among transgender women in Latin America: implementation, gaps and challenges. J Int AIDS Soc. 2016;19:20799.

8. Poteat T, Wirtz AL, Radix A, et al. HIV risk and preventive interventions in transgender women sex workers. Lancet. 2015;385:274-286.
9. Silva-Santisteban A, Raymond HF, Salazar X, et al. Understanding the HIV/ AIDS epidemic in transgender women of Lima, Peru: results from a seroepidemiologic study using respondent driven sampling. AIDS Behav. 2012;16:872-881.

10. Bastos Fl, Bastos LS, Coutinho C, et al. HIV, HCV, HBV, and syphilis among transgender women from Brazil: assessing different methods to adjust infection rates of a hard-to-reach, sparse population. Med Baltim. 2018; 97:S16-S24.

11. Grinsztejn B, Jalil EM, Monteiro L, et al. Unveiling of HIV dynamics among transgender women: a respondent-driven sampling study in Rio de Janeiro, Brazil. Lancet HIV. 2017;4:e169-e176.

12. Poteat T, German D, Flynn C. The conflation of gender and sex: gaps and opportunities in HIV data among transgender women and MSM. Glob Public Health. 2016;11:835-848.

13. Grinsztejn B, Veloso VG, Friedman RK, et al. Early mortality and cause of deaths in patients using HAART in Brazil and the United States. AIDS Lond Engl. 2009;23:2107-2114.

14. Quinn VP, Nash R, Hunkeler E, et al. Cohort profile: study of Transition, Outcomes and Gender (STRONG) to assess health status of transgender people. BMJ Open. 2017;7:e018121.

15. Williams B, Mancia G, Spiering W, et al. 2018 ESC/ESH Guidelines for the management of arterial hypertension. Eur Heart J. 2018;39:3021-3104.

16. American Diabetes Association (ADA). Introduction: standards of medical care in diabetes-2018. Diabetes Care. 2018;41:S1-S2.

17. Jellinger PS, Handelsman Y, Rosenblit PD, et al. American Association of Clinical Endocrinologists and American College of Endocrinology Guidelines for management of dyslipidemia and prevention of cardiovascular disease. Endocr Pract. 2017;23:1-87.

18. Garvey WT, Mechanick Jl, Brett EM, et al. American Association of Clinical Endocrinologists and American College of Endocrinology Comprehnesive Clinical Practice Guidelines for Medical Care of Patients with Obesity. Endocr Pract Off J Am Coll Endocrinol Am Assoc Clin Endocrinol. 2016;22: 842-884.

19. Andresen EM, Malmgren JA, Carter WB, et al. Screening for depression in well older adults: evaluation of a short form of the CES-D (Center for Epidemiologic Studies Depression Scale). Am J Prev Med. 1994;10: 77-84.

20. Zhang W, O'Brien N, Forrest Jl, et al. Validating a shortened depression scale (10 item CES-D) among HIV-positive people in British Columbia, Canada. PLoS One. 2012;7:e40793.

21. González P, Nuñez A, Merz E, et al. Measurement properties of the Center for Epidemiologic Studies Depression Scale (CES-D 10): findings from HCHS/SOL. Psychol Assess. 2017;29:372-381.

22. World Health Organization (WHO). WHO | The ASSIST Screening Test Version 3.0. WHO. 2005. www.who.int/substance_abuse/activities/assist_ test/en (accessed September 30, 2018).

23. Centers for Disease Control and Prevention. AIDS-Defining Conditions. 2008;57:9.

24. Kowalska JD, Friis-Møller N, Kirk O, et al. The coding causes of death in HIV (CoDe) project: initial results and evaluation of methodology. Epidemiology. 2011;22:516-523.

25. Pacheco AG, Saraceni V, Tuboi SH, et al. Validation of a hierarchical deterministic record-linkage algorithm using data from 2 different cohorts of human immunodeficiency virus-infected persons and mortality databases in Brazil. Am J Epidemiol. 2008;168:1326-1332.

26. Beltekian D, Ortiz-Ospina E. Extreme poverty is falling: How is poverty changing for higher poverty lines? March 5, 2018. https:// ourworldindata.org/poverty-at-higher-poverty-lines (accessed March 28, 2019).

27. Hembree WC, Cohen-Kettenis P, Delemarre-van de Waal HA, et al. Endocrine treatment of transsexual persons: an Endocrine Society clinical practice guideline. J Clin Endocrinol Metab. 2009;94:3132-3154.

28. Gardner IH, Safer JD. Progress on the road to better medical care for transgender patients. Curr Opin Endocrinol Diabetes Obes. 2013;20: 553-558.

29. Mahan RJ, Bailey TA, Bibb TJ, et al. Drug therapy for gender transitions and health screenings in transgender older adults. J Am Geriatr Soc. 2016; 64:2554-2559.

30. University of California, San Francisco. Guidelines for the primary and gender-affirming care of transgender and gender nonbinary people. http://transhealth.ucsf.edu/protocols (accessed October 4, 2018). 
31. Bishop BM. Pharmacotherapy considerations in the management of transgender patients: a brief review. Pharmacotherapy. 2015;35: 1130-1139.

32. Grant J, Mottet L, Tanis J, et al. Injustice at every turn: a report of the National Transgender Discrimination Survey. National Center for Trangender Equality, National Gay and Lesbion Task Force. 2011. Available at: www.ncgs.org/research/database/injustice-at-every-turn-a-report-of-thenational-trangender-discrimination-survey Accessed November 29, 2018.

33. Movement Advancement Project. A broken bargain for transgender workers. www.lgbtmap.org/policy-and-issue-analysis/transgenderworkers (accessed November 29, 2018).

34. UNESCO. Education sector responses to homophobic bullying. Good policy and practice in HIV and health education. Booklet 8. 2012. Available at: https://unesdoc.unesco.org/ark:/48223/pf0000216493 Accessed November 29, 2018.

35. Hiller R, Moreno A, Mallimaci A, et al. Cumbia, copeteo y lágrimas: informe nacional sobre la situación de las travestis transexuales y transgéneros. Buenos Aires: Asociación de Lucha por la Identidad Travesti-Transexual, A.L.I.T.T., 2007.

36. Divan V, Cortez C, Smelyanskaya M, et al. Transgender social inclusion and equality: a pivotal path to development. J Int AIDS Soc. 2016;19:20803.

37. Balzer C, LaGata C, Berredo L. TMM annual report 2016-an introduction to the Trans Murder Monitoring project. In: TvT Publication Series. 2016. www.tgeu.org (accessed November 29, 2018).

38. Nuttbrock L, Bockting W, Rosenblum A, et al. Gender abuse, depressive symptoms, and HIV and other sexually transmitted infections among male-to-female transgender persons: a three-year prospective study. Am J Public Health. 2013;103:300-307.

39. Nemoto $T$, Bödeker $B$, Iwamoto $M$, et al. Practices of receptive and insertive anal sex among transgender women in relation to partner types, sociocultural factors, and background variables. AIDS Care. 2014; 26:434-440.

40. Fleck MP, Lima AF, Louzada S, et al. [Association of depressive symptoms and social functioning in primary care service, Brazil]. Rev Saude Publica. 2002;36:431-438.

41. Munhoz TN, Nunes BP, Wehrmeister FC, et al. A nationwide populationbased study of depression in Brazil. J Affect Disord. 2016;192:226-233.

42. Steele LS, Daley A, Curling D, et al. LGBT identity, untreated depression, and unmet need for mental health services by sexual minority women and trans-identified people. J Womens Health Larchmt. 2017;26:116-127.

43. Jäggi $T$, Jellestad $L$, Corbisiero $S$, et al. Gender minority stress and depressive symptoms in transitioned Swiss transpersons. BioMed Res Int. 2018:2018:8639263.

44. Tebbe EA, Moradi B. Suicide risk in trans populations: an application of minority stress theory. J Couns Psychol. 2016;63:520-533.

45. Picon RV, Fuchs FD, Moreira LB, et al. Trends in prevalence of hypertension in Brazil: a systematic review with meta-analysis. PLoS One. 2012;7:e48255.

46. Telo GH, Cureau FV, de Souza MS, et al. Prevalence of diabetes in Brazil over time: a systematic review with meta-analysis. Diabetol Metab Syndr. 2016;8:65.

47. Lotufo PA, Santos RD, Figueiredo RM, et al. Prevalence, awareness, treatment, and control of high low-density lipoprotein cholesterol in Brazil: baseline of the Brazilian Longitudinal Study of Adult Health (ELSABrasil). J Clin Lipidol. 2016;10:568-576.

48. Rotondi NK, Bauer GR, Scanlon K, et al. Nonprescribed hormone use and self-performed surgeries: 'do-it-yourself' transitions in transgender communities in Ontario, Canada. Am J Public Health. 2013;103:18301836.

49. Wilson EC, Arayasirikul S, Johnson K. Access to HIV Care and Support Services for African American transwomen living with HIV. Int J Transgenderism. 2013;14:182-195.

50. Clark K, Fletcher JB, Holloway IW, et al. Structural inequities and social networks impact hormone use and misuse among transgender women in Los Angeles County. Arch Sex Behav. 2018;47:953-962.

51. de Haan G, Santos G-M, Arayasirikul S, et al. Non-prescribed hormone use and barriers to care for transgender women in San Francisco. LGBT Health. 2015;2:313-323.

52. Rapues J, Wilson EC, Packer T, et al. Correlates of HIV infection among transfemales, San Francisco, 2010: results from a respondent-driven sampling study. Am J Public Health. 2013;103:1485-1492.
53. Bellhouse C, Walker S, Fairley CK, et al. Patterns of sexual behaviour and sexual healthcare needs among transgender individuals in Melbourne, Australia, 2011-2014. Sex Transm Infect. 2018;94: 212-215.

54. World Professional Association for Transgender Health (WPATH). Standards of care for the health of transsexual, transgender, and gender nonconforming people. 2009. https://www.wpath.org/publications/soc (accessed September 8, 2018).

55. Gooren LJ, T'Sjoen G. Endocrine treatment of aging transgender people. Rev Endocr Metab Disord. 19:253-262.

56. Melendez RM, Exner TA, Ehrhardt AA, et al. Health and health care among male-to-female transgender persons who are HIV positive. Am J Public Health. 2006;96:1034-1037.

57. Sevelius JM, Carrico A, Johnson MO. Antiretroviral therapy adherence among transgender women living with HIV. J Assoc Nurses AIDS Care. 2010;21:256-264.

58. Sevelius JM, Patouhas E, Keatley JG, et al. Barriers and facilitators to engagement and retention in care among transgender women living with human immunodeficiency virus. Ann Behav Med. 2014;47:5-16.

Cite this article as: Ferreira ACG, Coelho LE, Jalil EM, Luz PM, Friedman RK, Guimarães MRC, Moreira RC, Eksterman LF, Cardoso SW, Castro CV, Derrico M, Moreira RI, Fernandes B, Monteiro L, Kamel L, Pacheco AG, Veloso VG, Grinsztejn B (2019) Transcendendo: A cohort study of HIV-infected and uninfected transgender women in Rio de Janeiro, Brazil, Transgender Health 4:1, 107-117, DOI: 10.1089/ trgh.2018.0063.

$\begin{aligned} & \text { Abbreviations Used } \\ & \mathrm{ART}=\text { antiretroviral therapy } \\ & \mathrm{ASSIST}=\text { Alcohol, Smoking and Substance Involvement } \\ & \quad \text { Screening Test } \\ & \mathrm{FHT}=\text { feminizing hormonal therapy } \\ & \mathrm{IDU}=\text { injection drug use } \\ & \mathrm{IM}=\text { intramuscular } \\ & \mathrm{IQR}=\text { interquartile range } \\ & \mathrm{LMIC}=\text { low- or middle-income country } \\ & \mathrm{RDS}=\text { respondent-driven sampling } \\ & \mathrm{SRS}=\text { sex reassignment surgeries } \\ & \mathrm{STI}=\text { sexually transmitted infection }\end{aligned}$

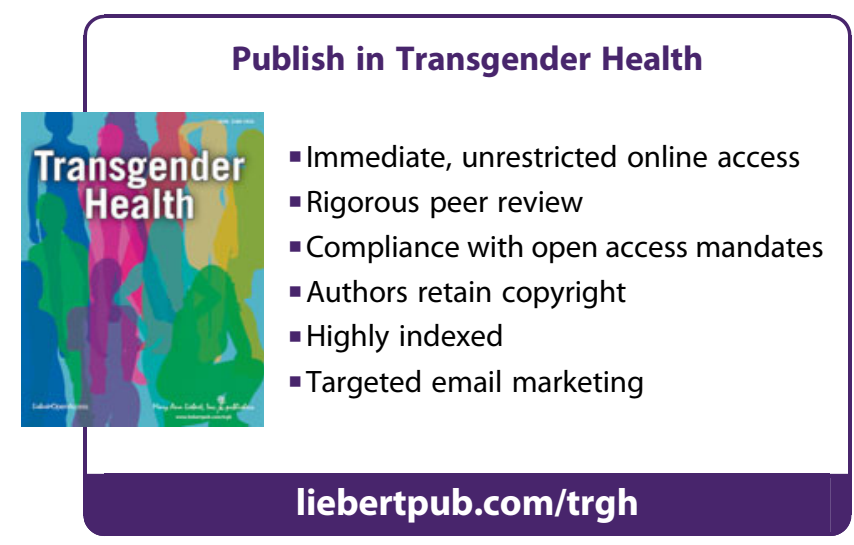

